\title{
Postoperative complications following simultaneous therapeutic and contralateral prophylactic nipple-sparing mastectomy: a retrospective study
}

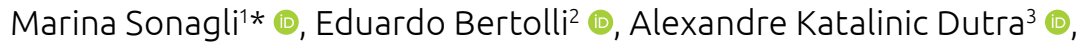 \\ Hirofumi lyeyasu ${ }^{1}$ (), Fabiana Baroni Alves Makdissi ${ }^{1}$ (i)
}

\section{ABSTRACT}

Introduction: Nipple-Sparing Mastectomy (NSM) is increasingly indicated for therapeutic and prophylactic purposes due to better cosmetic results with nipple maintenance. Postoperative complications have not been compared among patients who have undergone simultaneous therapeutic and contralateral prophylactic NSM. The aim of the present study was to evaluate the incidence and risk factors for postoperative complications in bilateral/unilateral NSMs, and therapeutic and/or prophylactic NSMs. Methods: Retrospective study of patients who underwent NSM between 2007 and 2017 at A.C. Camargo Cancer Center. Results: Among 290 patients, 367 NSMs were performed, 64 simultaneous therapeutic and contralateral prophylactic NSM. The latter were associated with more postoperative complications ( $O R=3.42 ; p=0.002$ ), mainly skin flap necrosis ( $O R=3.79 ; p=0.004)$, hematoma ( $O R=7.1 ; p=0.002$ ), wound infection ( $O R=3.45 ; p=0.012$ ), and nipple-areola complex (NAC) loss ( $O R=9.63 ; p=0.003)$. Of the 367 NSMs, 213 were unilateral NSMs, which were associated with lower rates of postoperative complications $(O R=0.44 ; p=0.003)$, especially skin flap necrosis ( $O R=0.32 ; p=0.001)$, hematoma ( $O R=0.29 ; p=0.008)$, wound infection $(O R=0.22 ; p=0.0001)$, and reoperation ( $O R=0.38 ; p=0.008$ ). Obesity was related to more postoperative complications $(O R=2.55 ; p=0.01)$, mainly hematoma $(O R=3.54 ; p=0.016)$, reoperation ( $O R=2.68 ; p=0.023)$, and NAC loss $(O R=3.54 ; p=0.016)$. Patients' age $(p=0.169)$, their smoking status ( $p=0.138)$, breast $p$ tosis $(0.189)$, previous chest radiotherapy ( $p 1)$, or previous breast surgery $(p=0.338)$ were not related to higher chances of postoperative complications. Conclusions: Results suggest that performing therapeutic and contralateral prophylactic NSM as separated procedures may represent a good strategy for minimizing postoperative complications.

KEYWORDS: subcutaneous mastectomy; postoperative complications; breast cancer; prophylactic mastectomy.

\section{INTRODUCTION}

Nipple-sparing mastectomy (NSM) consists of remove the mammary gland while preserving the skin envelope and the nipple-areola complex (NAC). ${ }^{1}$ The main advantage of preserving the NAC during NSM is to achieve better cosmetic results. ${ }^{2,3}$ However, this approach has been associated with postoperative complications in $12.4 \%-53.7 \%$ of cases. ${ }^{2,4-13}$ The main postoperative complications associated with NSM include skin flap necrosis, NAC necrosis, wound infection, wound dehiscence, implant removal due to infection or dehiscence, and hematoma which requires drainage. ${ }^{2,-13}$
NSM can be offered in different scenarios: bilateral risk-reducing (prophylactic) NSM for women who carry a genetic mutation which confers a higher risk of breast cancer; bilateral therapeutic NSM for patients with synchronous bilateral breast cancer; bilateral therapeutic NSM and contralateral prophylactic NSM for patients who carry a genetic mutation which can develop into breast cancer; unilateral therapeutic NSM; and unilateral prophylactic NSM. Previously, postoperative complications between bilateral and unilateral $\mathrm{NSM},{ }^{7,13}$ and between therapeutic and prophylactic NSM ${ }^{3,6,11}$ have been examined. However, to date, all of the scenarios listed above have not been compared. Therefore, the

'Breast Cancer Department, A.C. Camargo Cancer Center - São Paulo (SP), Brazil

2Skin Cancer Department, A.C. Camargo Cancer Center - São Paulo (SP), Brazil

${ }^{3}$ Plastic and Reconstructive Surgery Department, A.C. Camargo Cancer Center - São Paulo (SP), Brazil

*Corresponding author: marina.sonagli@accamargo.org.br

Conflict of interests: nothing to declare.

Received on: 07/11/2020. Accepted on: 01/04/2021 
aim of the present study was to compare postoperative complications of bilateral or unilateral NSM, and prophylactic and/or therapeutic NSM, and determine which risk factors are associated with NSM's postoperative complications.

\section{MATERIALS AND METHODS}

This retrospective study examined patients who underwent NSM at A.C. Camargo Cancer Center between January 2007 and December 2017. Male patients, patients treated at another institution, and patients whose data could not be retrieved from medical records were excluded. Prophylactic NSM was considered for patients without breast diseases or with a previous biopsy of Lobular Carcinoma in situ. Therapeutic NSM was considered for treatment of ductal carcinoma in situ and invasive carcinoma. Both sides of bilateral NSM were performed by the same team of surgeons. Postoperative complications considered were those that appeared within 90 days of surgery. Research was approved by the Research Ethics Committee of A.C. Camargo Cancer Center.

Statistical analyses were performed by using SPSS version 20.0 software for Windows (Chicago, IL, USA). Statistical significance was set at $p<0.05$. Descriptive statistical methods were used to compare clinical characteristics of the patients and postoperative complications of NSM. Chi-square or Fisher's exact tests, Student's t-test, and the Mann-Whitney U test were used to evaluate associations between measures. Simple and multiple logistic regression were used to identify significant predictors of developing complications.

\section{RESULTS}

A total of 367 NSMs were performed in 290 patients for treatment of breast cancer or for risk-reduction between January 2007 and December 2017 at A.C. Camargo Cancer Center. Of these NSM procedures, 154 (42\%) were bilateral, with 74/154 (48\%) being prophylactic NSMs, 16/154 (10.4\%) being therapeutic, and 64/154 (41.6\%) being therapeutic and contralateral prophylactic NSMs (Figure 1).

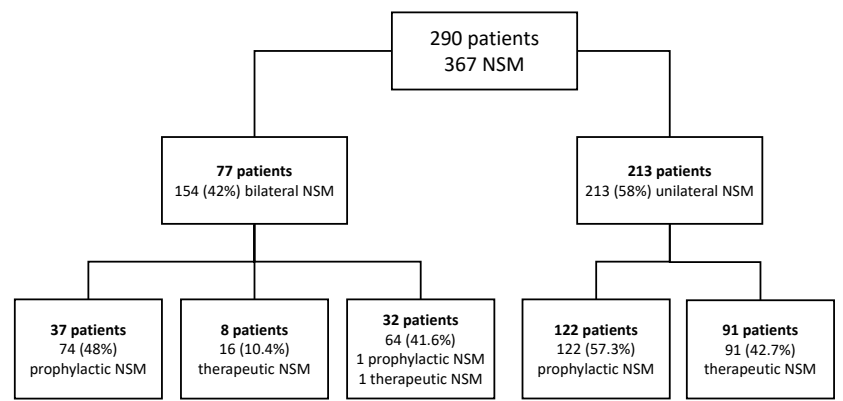

Figure 1. Number of patients and nipple-sparing mastectomies (NSM) performed at A.C. Camargo Cancer Center between January 2007 and December 2017.
The mean age of the cohort examined was 47 years (range 26-74), 29 (10\%) were smokers and 43 (14.8\%) were former smokers, 35 (12.1\%) were obese, and $172(59.3 \%)$ were premenopausal. The most prevalent comorbidities included hypothyroidism (19.3\%), systemic arterial hypertension (15.9\%), dyslipidemia (9.3\%), and diabetes (5.9\%) (Supplementary Table 1).

The overall complication rate for the cohort was 40\% ( $\mathrm{n}=116)$. Among the 213 patients who underwent unilateral NSM, 74 (34.7\%) developed postoperative complications. Meanwhile, 42/77 (54.5\%) patients who underwent bilateral NSM presented postoperative complications. According to indication, postoperative complications were reported for: $32.7 \%$ (52/159) of patients undergoing prophylactic NSM, 44.4\% (44/99) of patients undergoing therapeutic NSM, and $62.5 \%$ (20/32) of patients undergoing simultaneous therapeutic and contralateral prophylactic NSM. Among the 72 patients with a current or previous smoking habit, 44 (61.1\%) developed postoperative complications. Among the 35 obese patients, 21 (60\%) presented postoperative complications. Breast ptosis was also evaluated, and postoperative complications were observed in 26 (35.6\%), $23(41.1 \%)$, and 16 (57.1\%) patients exhibiting mild, moderate, and accentuated breast ptosis, respectively. A total of 16 patients had a history of chest wall radiotherapy (RT), with six (37.5\%) developing postoperative complications. Finally, among the 75 patients who previously underwent breast surgery, 34 (45.3\%) presented postoperative complications. Overall, only bilateral/unilateral NSMs $(\mathrm{p}=0.004)$, therapeutic and/or prophylactic NSMs $(\mathrm{p}=0.004)$, and obesity $(\mathrm{p}=0.015)$ showed statistically significant differences for postoperative complications (Table 1).

A simple logistic regression analysis showed that unilateral NSM was associated with a lower chance of postoperative complications $(\mathrm{OR}=0.44$; $95 \%$ confidence interval $(95 \% \mathrm{CI})$ $0.26-0.75 ; p=0.003$ ), whereas patients who underwent therapeutic and contralateral prophylactic NSM during the same surgery had three times higher chance of developing postoperative complications (OR=3.42; 95\% CI 1.55-7.54; $\mathrm{p}=0.002)$. This association was further corroborated by multiple logistic regressions (OR=3.12; 95\% CI 1.09-8.95; $\mathrm{p}=0.03$ ). Both simple and multiple logistic regression analyses also demonstrated that obese patients had a greater chance of developing postoperative complications $(\mathrm{OR}=2.55$; 95\%CI 1.24-5.25, $\mathrm{p}=0.01$; and $\mathrm{OR}=3.57 ; 95 \%$ CI 1.33-9.55; $\mathrm{p}=0.01$, respectively) (Table 1 ). When evaluating if age contributed to postoperative complications, the mean age of women who developed postoperative complications versus those who did not was not significantly different $(\mathrm{p}=0.169)$, even when compared according to age groups $(\mathrm{p}=0.131)$ (Supplementary Table 2).

Complications were categorized as follows: partial or total NAC necrosis (21.7\%), partial or total wound dehiscence (21.4\%), partial or total skin flap necrosis (14.5\%), wound infection 
Table 1. Associations between risk factors and postoperative complications in patients who underwent nipple-sparing mastectomy (NSM).

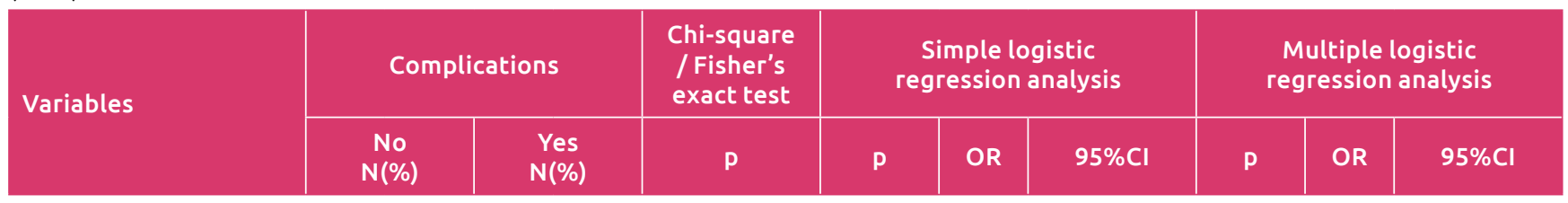

Laterality

\begin{tabular}{|c|c|c|c|c|c|c|c|c|c|c|c|}
\hline Bilateral & 35 & 45.5 & 42 & 54.5 & $0.004 *$ & & Ref & & & Ref & \\
\hline Unilateral & 139 & 65.3 & 74 & 34.7 & & $0.003 *$ & 0.44 & $0.26-0.75$ & 0.449 & 0.69 & $0.26-1.78$ \\
\hline \multicolumn{12}{|l|}{ Indication } \\
\hline Prophylactic & 107 & 67.3 & 52 & 32.7 & $0.004^{*}$ & & Ref & & & Ref & \\
\hline Therapeutic & 55 & 55.6 & 44 & 44.4 & & 0.059 & 1.64 & $0.98-2.76$ & 0.62 & 1.18 & $0.60-2.35$ \\
\hline $\begin{array}{l}1 \text { Breast prophylactic } \\
\text { and } 1 \text { Breast } \\
\text { therapeutic }\end{array}$ & 12 & 37.5 & 20 & 62.5 & & $0.002 *$ & 3.42 & $1.55-7.54$ & $0.03^{*}$ & 3.12 & $1.09-8.95$ \\
\hline \multicolumn{12}{|l|}{ Smoking status } \\
\hline Non-smoker & 136 & 62.7 & 81 & 37.3 & 0.138 & & Ref & & & & \\
\hline Smoker & 18 & 62.1 & 11 & 37.9 & & 0.95 & 1 & $0.46-2.28$ & & & \\
\hline Former Smoker & 20 & 46.5 & 23 & 53.5 & & 0.05 & 1,9 & $0.99-3.73$ & & & \\
\hline \multicolumn{12}{|l|}{ Obesity } \\
\hline No & 160 & 63.0 & 94 & 37.0 & 0.015 * & & Ref & & & Ref & \\
\hline Yes & 14 & 40.0 & 21 & 60.0 & & $0.01 *$ & 2.55 & $1.24-5.25$ & $0.01 *$ & 3.57 & $1.33-9.55$ \\
\hline \multicolumn{12}{|l|}{ Breast ptosis } \\
\hline No & 10 & 71.4 & 4 & 28.6 & 0.189 & & Ref & & & & \\
\hline Mild & 47 & 64.4 & 26 & 35.6 & & 0.612 & 1.38 & $0.39-4.84$ & & & \\
\hline Moderate & 33 & 58.9 & 23 & 41.1 & & 0.394 & 1.74 & $0.48-6.24$ & & & \\
\hline Accentuated & 12 & 42.9 & 16 & 57.1 & & 0.087 & 3.33 & $0.83-13.25$ & & & \\
\hline \multicolumn{12}{|c|}{ Previous chest Radiotherapy } \\
\hline No & 164 & 59.9 & 110 & 40.1 & 1 & & Ref & & & & \\
\hline Yes & 10 & 62.5 & 6 & 37.5 & & 0.834 & 0.89 & $0.31-2.53$ & & & \\
\hline \multicolumn{12}{|l|}{ Previous breast surgery } \\
\hline No & 133 & 61.9 & 82 & 38.1 & 0.338 & & Ref & & & & \\
\hline Yes & 41 & 54.7 & 34 & 45.3 & & 0.274 & 1.34 & $0.79-2.28$ & & & \\
\hline
\end{tabular}

OR: odds ratio; Cl: confidence interval; * $\mathrm{p}<0.05$.

(10.3\%), and hematoma (7.2\%). A total of $38(13.1 \%)$ women needed reoperations. The NAC was excised in $20(6.9 \%)$ cases, $13(4.5 \%)$ due to total necrosis, five (1.7\%) due to the presence of invasive carcinoma in the retroareolar margin, and two $(0.7 \%)$ due to the presence of carcinoma in situ in the retroareolar margin (Table 2).

The present data demonstrated that bilaterality, simultaneous therapeutic and contralateral prophylactic NSM, and obesity are factors associated with a higher risk of postoperative complications. Comparing to patients who underwent unilateral NSM, those who underwent bilateral NSM presented a greater incidence of skin flap necrosis ( $26 \mathrm{vs.} 10.3 \%$, respectively; $\mathrm{p}=0.002$ ), hematoma (14.3 vs. 4.7\%, respectively; $\mathrm{p}=0.012)$, wound infection ( 22.1 vs. $6.1 \%$, respectively; $\mathrm{p}=0.0001)$, and reoperation $(22.1 \%$ vs. $9.9 \%$, respectively; $\mathrm{p}=0.012$ ) (Table 2). Logistic regression analysis identified unilateral NSM as a protective factor for skin flap necrosis $(\mathrm{OR}=0.32$; $95 \% \mathrm{CI} 0.16-0.64 ; \mathrm{p}=0.001)$, hematoma $(\mathrm{OR}=0.29$; $95 \%$ CI $0.12-0.72 ; \mathrm{p}=0.008)$, wound infection $(\mathrm{OR}=0.22 ; 95 \% \mathrm{CI}$ $0.10-0.49 ; \mathrm{p}=0.0001)$, and reoperation $(\mathrm{OR}=0.38 ; 95 \% \mathrm{CI} 0.19-0.77$; $\mathrm{p}=0.008)$ (Table 3). 
Table 2. Associations between risk factors and types of postoperative complications in patients who underwent nipple-sparing mastectomy (NSM).

\begin{tabular}{|c|c|c|c|c|c|c|c|c|c|c|c|c|c|c|}
\hline $\begin{array}{l}\text { No. patients who } \\
\text { underwent NSM }\end{array}$ & \multicolumn{2}{|c|}{$\begin{array}{c}\text { NAC } \\
\text { necrosis } \\
\text { N\% }\end{array}$} & \multicolumn{2}{|c|}{$\begin{array}{c}\text { Skin flap } \\
\text { necrosis } \\
\text { N\% }\end{array}$} & \multicolumn{2}{|c|}{$\begin{array}{c}\text { Hematoma } \\
\mathrm{N} \%\end{array}$} & \multicolumn{2}{|c|}{$\begin{array}{c}\text { Wound } \\
\text { infection } \\
\mathrm{N} \%\end{array}$} & \multicolumn{2}{|c|}{$\begin{array}{c}\text { Wound } \\
\text { dehiscence } \\
\text { N\% }\end{array}$} & \multicolumn{2}{|c|}{$\begin{array}{c}\text { Reoperation } \\
\text { N\% }\end{array}$} & \multicolumn{2}{|c|}{$\begin{array}{l}\text { NAC } \\
\text { Loss } \\
\text { N\% }\end{array}$} \\
\hline Overall $(n=290)$ & 63 & 21.7 & 42 & 14.5 & 21 & 7.2 & 30 & 10.3 & 62 & 21.4 & 38 & 13.1 & 20 & 6.9 \\
\hline Laterality & \multicolumn{2}{|c|}{0.803} & \multicolumn{2}{|c|}{$0.002 *$} & \multicolumn{2}{|c|}{$0.012 *$} & \multicolumn{2}{|c|}{$0.0001 *$} & \multicolumn{2}{|c|}{0.324} & \multicolumn{2}{|c|}{$0.012 *$} & \multicolumn{2}{|c|}{0.532} \\
\hline Bilateral $(n=77)$ & 18 & 23.4 & 20 & 26 & 11 & 14.3 & 17 & 22.1 & 20 & 26 & 17 & 12.1 & 7 & 9.1 \\
\hline Unilateral $(n=213)$ & 45 & 21.1 & 22 & 10.3 & 10 & 4.7 & 13 & 6.1 & 42 & 19.7 & 21 & 9.9 & 13 & 6.1 \\
\hline Indication & \multicolumn{2}{|c|}{0.169} & \multicolumn{2}{|c|}{$0.011 *$} & \multicolumn{2}{|c|}{$0.003 *$} & \multicolumn{2}{|c|}{$0.015^{*}$} & \multicolumn{2}{|c|}{0.435} & \multicolumn{2}{|c|}{0.280} & \multicolumn{2}{|c|}{$0.001^{*}$} \\
\hline Prophylactic ( $n=159$ ) & 28 & 17.6 & 17 & 10.7 & 5 & 3.1 & 14 & 8.8 & 30 & 18.9 & 20 & 12.6 & 3 & 1.9 \\
\hline Therapeutic $(n=99)$ & 26 & 26.3 & 15 & 15.2 & 10 & 10.1 & 8 & 8.1 & 23 & 23.2 & 11 & 11.1 & 12 & 12.1 \\
\hline $\begin{array}{l}1 \text { Breast prophylactic }+1 \\
\text { Breast therapeutic }(n=32)\end{array}$ & 9 & 28.1 & 10 & 31.3 & 6 & 18.8 & 8 & 25 & 9 & 28.1 & 7 & 21.9 & 5 & 15.6 \\
\hline Obesity & \multicolumn{2}{|c|}{0.382} & \multicolumn{2}{|c|}{0.217} & \multicolumn{2}{|c|}{$0.022^{*}$} & \multicolumn{2}{|c|}{0.139} & \multicolumn{2}{|c|}{0.663} & \multicolumn{2}{|c|}{$0.03 *$} & \multicolumn{2}{|c|}{$0.022 *$} \\
\hline No $(n=254)$ & 52 & 20.5 & 34 & 13.4 & 14 & 5.5 & 23 & 9 & 53 & 20.9 & 29 & 11.4 & 14 & 5.6 \\
\hline Yes $(n=35)$ & 10 & 28.6 & 8 & 22.8 & 6 & 17.1 & 6 & 17.1 & 9 & 25.7 & 9 & 25.7 & 6 & 17.1 \\
\hline
\end{tabular}

NSM: nipple-sparing mastectomy, NAC: nipple-areola complex. Chi-square/Fisher's exact test *p<0.05.

Table 3. Associations between risk factors and postoperative complications of nipple-sparing mastectomy (NSM).

\begin{tabular}{|c|c|c|c|c|}
\hline \multirow{2}{*}{ Risk Factors } & \multirow{2}{*}{ Outcome } & \multicolumn{3}{|c|}{ Simple Logistic Regression Analysis } \\
\hline & & OR & $95 \% \mathrm{Cl}$ & $\mathbf{p}$ \\
\hline Therapeutic & \multirow{3}{*}{ Skin flap necrosis } & 1.49 & $0.70-3.14$ & 0.293 \\
\hline Prophylactic+therapeutic & & 3.79 & $1.54-9.34$ & $0.004 *$ \\
\hline Unilateral & & 0.32 & $0.16-0.64$ & $0.001^{*}$ \\
\hline Therapeutic & \multirow{4}{*}{ Hematoma } & 3.46 & $1.14-10.44$ & $0.02 *$ \\
\hline Prophylactic+therapeutic & & 7.10 & $2.02-24.99$ & $0.002 *$ \\
\hline Unilateral & & 0.29 & $0.12-0.72$ & $0.008^{*}$ \\
\hline Obesity & & 3.54 & $1.26-9.94$ & $0.016^{*}$ \\
\hline Therapeutic & \multirow{3}{*}{ Wound infection } & 0.91 & $0.36-2.25$ & 0.84 \\
\hline Prophylactic+therapeutic & & 3.45 & $1.30-9.10$ & $0.012 *$ \\
\hline Unilateral & & 0.22 & $0.10-0.49$ & $0.0001 *$ \\
\hline Unilateral & \multirow{2}{*}{ Reoperation } & 0.38 & $0.19-0.77$ & $0.008^{*}$ \\
\hline Obesity & & 2.68 & $1.14-6.29$ & $0.023 *$ \\
\hline Therapeutic & \multirow{3}{*}{ NAC loss } & 7.17 & $1.97-26.1$ & $0.003 *$ \\
\hline Prophylactic+therapeutic & & 9.63 & $2.17-42.6$ & $0.003 *$ \\
\hline Obesity & & 3.54 & $1.26-9.94$ & $0.016^{*}$ \\
\hline
\end{tabular}

NAC: nipple-areola complex; OR: odds ratio; Cl: confidence interval. * $\mathrm{p}<0.05$

Women who underwent simultaneous therapeutic NSM and contralateral prophylactic NSM developed a greater number of complications than those who underwent therapeutic NSM or prophylactic NSM. For these three groups, significant differences in skin flap necrosis $(31.3 \%, 15.2 \%$, and $10.7 \%$, respectively; $\mathrm{p}=0.011)$, hematoma $(18.8 \%, 10.1 \%$, and $3.1 \%$, respectively; $\mathrm{p}=0.003)$, wound infection $(25,18.8$, and $10.1 \%$, respectively; $\mathrm{p}=0.015)$, and NAC loss $(15.6 \%, 12.1 \%$, and $1.9 \%$, respectively; $\mathrm{p}=0.001)$ were observed (Table 2). Furthermore, patients who underwent therapeutic NSM and contralateral prophylactic NSM during the same surgery had three times higher chance of developing skin flap necrosis ( $\mathrm{OR}=3.79 ; 95 \% \mathrm{CI} 1.54-9.34 ; \mathrm{p}=0.004)$ and wound infection 
$(\mathrm{OR}=3.45 ; 95 \% \mathrm{CI} 1.3-9.1 ; \mathrm{p}=0.012)$. However, this increased risk was not observed for patients who underwent therapeutic NSM. Regarding hematoma and NAC loss, a higher chance of developing these complications was associated with patients undergoing simultaneous therapeutic and contralateral prophylactic NSM or therapeutic NSM. Compared to women who underwent prophylactic NSM, the chance of developing a hematoma was higher for those who underwent therapeutic NSM (OR=3.46; 95\%CI 1.14-10.44; $\mathrm{p}=0.02$ ), and even higher for women who underwent simultaneous therapeutic NSM and contralateral prophylactic NSM (OR=7.1; 95\%CI 2.02-24.99; $\mathrm{p}=0.002)$. A similar profile was observed regarding NAC loss, with seven times higher chance observed for patients who underwent therapeutic NSM (OR=7.17; 95\%CI 1.9-26.1; $\mathrm{p}=0.003$ ) and nine times higher chance for patients who underwent simultaneous therapeutic and contralateral prophylactic NSM (OR=9.63; 95\%CI 2.1-42.6; $\mathrm{p}=0.003)$, compared to patients who underwent prophylactic NSM (Table 3).

Obese patients presented the greatest number of overall complications, although a statistically significant association with obesity was only observed for hematoma (17.1\% vs. 5.5\%, respectively; $\mathrm{p}=0.02)$, reoperation rate $(25.7 \%$ vs. $11.4 \%$, respectively; $\mathrm{p}=0.03$ ), and loss ( $17.1 \%$ vs. $5.6 \%$, respectively; $\mathrm{p}=0.02)$ (Table 2 ). Obese patients had three times higher chance of developing hematoma and NAC loss (OR=3.54; 95\%CI 1.26-9.94; $\mathrm{p}=0.016)$ and two times higher chance of needing reoperation $(\mathrm{OR}=2.68$; 95\%CI 1.26-9.94; $\mathrm{p}=0.016$ ) (Table 3).

Among the 13 patients treated with neoadjuvant chemotherapy (NCT), no postoperative complications were reported $(\mathrm{p}=0.138)$. Meanwhile, among 131 patients who underwent therapeutic NSM, 47 (35.9\%) received adjuvant treatment with hormone therapy (HT) alone, eight $(6 \%)$ received radiotherapy alone, three $(2.3 \%)$ received chemotherapy (CT) alone, $21(16 \%)$ received CT and HT, 17 (13\%) received RT, CT, and HT, 14 (10.7\%) did not receive any adjuvant treatment, and data for two patients were not available (Supplementary Table 3). Patients who received only adjuvant radiotherapy have been treated with NCT. The start of adjuvant treatment did not significantly differ among the patients who underwent unilateral or bilateral $\operatorname{NSM}(\mathrm{p}=0.078)$, or among those who underwent therapeutic or simultaneous therapeutic and contralateral prophylactic NSM $(\mathrm{p}=0.449)$ (Table 4).

\section{DISCUSSION}

An increased demand for specialized breast cancer services has been reported worldwide, after the Angelina Jolie Effect. ${ }^{14}$ In addition, studies have shown a trend towards a progressive increase in bilateral risk-reducing NSM and contralateral NSM in patients who have already undergone mastectomy for cancer treatment. ${ }^{15,16}$ A recent study has further demonstrated a growth trend in the indication of NSM, not only for risk-reduction, but also for treatment of larger tumors. ${ }^{17}$

Cosmetic contraindications of NSM include factors associated with postoperative complications which impact cosmetic results and the malposition of NAC. Both large breast size and breast ptosis are reported to be absolute cosmetic contraindications of NSM, due to the difficulties associated with managing a large skin envelope. ${ }^{18}$ Breasts heavier than $800 \mathrm{~g}$ also present two to five times greater chance of developing postoperative complications. ${ }^{19,20}$ In the present study, obesity (defined as body mass index $(\mathrm{BMI})>30 \mathrm{~cm} / \mathrm{m}^{2}$ ) was associated with two to three times higher chance of developing postoperative complications. In order to expand NSM indications, reconstruction of large and ptotic breasts can be managed by using a staged approach, with mastopexy or reduction performed prior to NSM in prophylactic surgery candidates. ${ }^{21}$

Increased BMI, diabetes mellitus, smoking, previous breast incisions, prior chest or breast radiotherapy, and NCT have been identified as relative contraindications for NSM. 2,8,10,11,18,20,22 In the present study, no associations between patient's age, smoking status, breast ptosis, prior chest radiotherapy, or prior breast surgery were observed for NSM postoperative complications.

There are few studies which have compared postoperative complications between bilateral and unilateral NSMs, and none of them found statistical differences between laterality and the incidence of postoperative complications. ${ }^{7,13}$ In a study conducted by Wang et al., 51 unilateral and 166 bilateral NSMs were compared to 187 unilateral and 394 bilateral Skin-Sparing Mastectomy. Bilateral surgery was found to be associated with a longer hospital stay, yet it was not associated with higher complications rates. ${ }^{13}$ In contrast, cases of unilateral NSM examined in the present study were associated with a lower rate of postoperative complications.

Previously, NSM postoperative complication rates have been reported to range up to $53.7 \%{ }^{7}$ In the present study, the overall

Table 4. Time to start of chemotherapy and/or adjuvant radiotherapy in patients who underwent unilateral/bilateral therapeutic nipple-sparing mastectomy (NSM) and therapeutic/ simultaneous therapeutic and contralateral prophylactic NSM.

\begin{tabular}{l|c|c}
\multirow{2}{*}{ Therapeutic NSM } & $\begin{array}{c}\text { Time to start of } \\
\text { adjuvant treatment } \\
\text { (months) }\end{array}$ & $\begin{array}{c}\text { Mann-Whitney } \\
\text { U test }\end{array}$ \\
\cline { 1 - 2 } Bean \pm SD (range) & $\boldsymbol{P}$ \\
\cline { 1 - 2 } Bilateral & $2.1 \pm 1.48(0-5)$ & \multirow{2}{*}{0.078} \\
\hline Unilateral & $1.5 \pm 1.1(0-4)$ & \multirow{2}{*}{0.449} \\
\hline $\begin{array}{l}\text { Therapeutic Unilateral } \\
\text { 1 Breast Prophylactic }+\end{array}$ & $1.64 \pm 1.2(0-5)$ & \\
\hline
\end{tabular}

NSM: nipple-sparing mastectomy, SD: standard deviation. ${ }^{*} p<0.05$. 
complication rate was $40 \%$, consistent with the published literature. However, the relation between indications of NSM and postoperative complications remains controversial. Mitchell et al. compared 833 therapeutic NSM and 1,102 prophylactic NSM, and found that therapeutic NSM was associated with a greater incidence of flap infections. ${ }^{3}$ However, other studies have not found differences between indications (therapeutic/prophylactic) of NSM and postoperative complications. ${ }^{6,11}$ To the best of our knowledge, the present study is the first to include a third group for comparison: patients who undergo therapeutic and contralateral prophylactic NSM during the same operation. We observed that this third group presented a greater number of postoperative complications, followed by therapeutic NSM alone and prophylactic NSM alone. We also observed that patients who underwent therapeutic and contralateral prophylactic NSM presented three-fold greater chance of experiencing postoperative complications.

NAC necrosis is a significantly adverse postoperative complication of NSM. Rates of NAC necrosis have been reported to range from $0.8 \%-29.6 \% .^{2,4-11,13,16,17,2,23,24}$ However, not all cases of NAC necrosis require operation and NAC excision. Wagner et al. reported rates of NAC necrosis up to $29.6 \%,{ }^{10}$ although most of these cases involved partial NAC necrosis (20.3\%) and only 7.4\% of the cases required NAC excision. ${ }^{7}$ Similarly, Garcia-Etienne et al. described a NAC necrosis rate of $48 \%$, yet only $5 \%$ of these cases were removed due to total NAC necrosis. ${ }^{25}$ In the present study, NAC desquamation was grouped with partial and total necrosis, resulting in a NAC necrosis rate of $21.7 \%$. However, only $4.5 \%$ of the NACs needed to be excised due to total NAC necrosis. Smoking and obesity have also been described as risk factors for NAC necrosis. ${ }^{10,26}$ In the present study, NAC necrosis was not found to be related to these or other factors.

Skin flap necrosis is another relatively common postoperative complication of NSM, with incidence rates ranging from $1.5 \%-37.5 \%{ }^{2,4,6-11,23}$. Just like NAC necrosis, not all cases of skin flap necrosis require surgical debridement. In the present study, partial and total skin flap necrosis were grouped, resulting in a skin flap necrosis rate of $14.5 \%$. Factors reported to be associated to skin flap necrosis in NSM are prior breast surgery, prior breast radiotherapy, duration of surgery, sharp dissection, and specimen size. ${ }^{10,27}$ In the present study, neither prior breast surgery nor prior breast radiotherapy were identified as risk factors. However, women who underwent therapeutic and contralateral prophylactic NSM had three-fold higher chance of developing skin flap necrosis. In contrast, women who underwent unilateral NSM had a $68 \%$ lower chance of developing skin flap necrosis.

Wound dehiscence rates after NSM have been reported to range from $1.9 \%-7.7 \%{ }^{7,10,13,23}$ In the present study, wound dehiscence rate was $21.4 \%$. This higher rate may be due to our consideration of any wound dehiscence when calculating this rate, not only those which required a second operation. Besides that, no risk factors associated with a higher risk of wound dehiscence were identified.

Regarding hematoma as a postoperative complication of NSM, we observed that patients who underwent unilateral NSM had a $71 \%$ lower chance for developing this complication. Furthermore, we observed that patients who underwent therapeutic NSM had three-fold higher chance of presenting hematoma, whereas patients undergoing therapeutic and contralateral prophylactic NSM during the same surgery increased the chance to sevenfold. To the best of our knowledge, we believe the present study is the first to demonstrate an association between laterality and indication (prophylactic/therapeutic) of NSM with hematoma. All patients who underwent NSM received the same thromboembolic prophylaxis.

Two studies have investigated an association between wound infection and indication of NSM. Whereas Spear et al. did not find differences between postoperative infections and therapeutic or prophylactic NSM, ${ }^{6}$, Mitchell et al. showed a higher infection rate after therapeutic NSM. ${ }^{3}$ In the present study, patients who underwent therapeutic and contralateral prophylactic NSM during the same surgery had a three-fold higher chance of wound infection. Conversely, unilateral NSM was found to be associated with a $78 \%$ lower chance of developing postoperative infection.

Reoperation rates of NSM to treat postoperative complications are reported to range from $4.2 \%-9.4 \%,{ }^{8,13,17}$ The overall reoperation rate in the present study was $13.1 \%$. Excluding patients who underwent reoperation to excise NAC due to involvement of the retroareolar margin with carcinoma, the reoperation rate found in this study to treat postoperative complications was $10.7 \%$, which is close to the rates reported in other studies. ${ }^{8,13,17}$ We further observed that obese patients had two-fold higher chance of reoperation after NSM.

A delay in the start of adjuvant treatment of up to two months after surgery proved to be related to a worse overall survival (OS) in patients with disease stage III, triple-negative and HER2 positive tumors, and a worse disease-free survival (DFS) in patients with disease stage III. ${ }^{28}$ Worse OS and DFS have also been reported for patients who received adjuvant radiotherapy 2.3 months and 3 months after surgery, respectively. ${ }^{29}$ Riba et al. showed that patients older than 70 years old, with hospital readmission within 30 days after surgery, positive margins after conservative breast surgery, reconstruction with autologous flap, and mastectomy were factors associated with a beginning of adjuvant treatment three months after surgery. In this study, bilateral mastectomy was not associated with a greater chance of delaying systemic treatment; ${ }^{30}$ patients who underwent bilateral NSM, therapeutic NSM, or simultaneous therapeutic and contralateral prophylactic NSM, despite having higher risks of postoperative complications, did not have a delay in adjuvant treatment. 
Type of breast reconstruction, operative time, and type of dissection (sharp or electrocautery) were not evaluated and consist a limitation of this study. However, our results can be used to discuss with patients which moment is the best to perform the prophylactic NSM.

\section{CONCLUSIONS}

We conclude that therapeutic and contralateral prophylactic NSM performed in the same surgery is associated with more postoperative complications, mainly skin flap necrosis, hematoma, wound infection, and NAC loss. Obesity was also observed to be associated with an increased risk of hematoma, reoperation, and NAC loss. Despite major postoperative complications, we observed that laterality (bilateral/ unilateral) and purpose (prophylactic/therapeutic) were not associated with delay in starting adjuvant treatment. When analyzed together, these results suggest that performing therapeutic NSM and contralateral prophylactic NSM at different times as separate procedures could minimize the incidence of postoperative complications, especially for obese patients.

\section{ACKNOWLEDGMENTS}

We thank A.C. Camargo Cancer Center for giving permission to use its database of medical records, Silvana Soares dos Santos for her support with the initial database research performed, and Barbara Bettim for her support with statistical analyses.

\section{AUTHORS' CONTRIBUTIONS}

M.S.: conceptualization, investigation, methodology, project administration, data curation, writing original draft, writing review \& editing; E.B.: formal analysis, visualization, writing - review \& editing; A.K.D.: visualization, writing - review \& editing; H.I.: writing - review \& editing; F.B.A.M.: conceptualization, formal analysis, investigation, methodology, validation, writing - review \& editing.

\section{REFERENCES}

1. Freeman MD, Gopman JM, Salzberg CA. The evolution of mastectomy surgical technique: from mutilation to medicine. Gland Surg. 2018;7(3):308-15. https://doi.org/10.21037/ gs.2017.09.07

2. De Vita R, Zoccali G, Buccheri EM, Costantini M, Botti C, et al. Outcome evaluation after 2023 nipple-sparing mastectomies: our experience. Plast Reconstr Surg. 2017;139(2):345e-47e. https://doi.org/10.1097/PRS.0000000000003027

3. Mitchell SD, Willey SC, Beitsch P, Feldman S. Evidence based outcomes of the american society of breast surgeons nipple sparing mastectomy registry. Gland Surg. 2018;7(3):247-57. https://doi.org/10.21037/gs.2017.09.10

4. Sacchini V, Pinotti JA, Barros ACSD, Luini A, Pluchinotta A, et al. Nipple-sparing mastectomy for breast cancer and risk reduction: oncologic or technical problem? J Am Coll Surg. 2006;203(5):70414. https://doi.org/10.1016/j.jamcollsurg.2006.07.015

5. Petit JY, Veronesi U, Orecchia R, Rey P, Martella S, et al. Nipple sparing mastectomy with nipple areola intraoperative radiotherapy: one thousand and one cases of a five years experience at the European institute of oncology of Milan (EIO). Breast Cancer Res Treat. 2009;117(2):333-8. https://doi. org/10.1007/s10549-008-0304-y

6. Spear SL, Willey SC, Feldman ED, Cocilovo C, Sidawy M, et al. Nipple-sparing mastectomy for prophylactic and therapeutic indications. Plast Reconstr Surg. 2011;128(5):1005-14. https:// doi.org/10.1097/PRS.0b013e31822b6456

7. Wagner JL, Fearmonti R, Hunt KK, Hwang RF, Meric-Bernstam F, et al. Prospective evaluation of the nipple-areola complex sparing mastectomy for risk reduction and for early-stage breast cancer. Ann Surg Oncol. 2012;19(4):1137-44. https://doi. org/10.1245/s10434-011-2099-z
8. Colwell AS, Tessler O, Lin AM, Liao E, Winograd J, et al. Breast reconstruction following nipple-sparing mastectomy: Predictors of complications, reconstruction outcomes, and 5-year trends. Plast Reconstr Surg. 2014;133(3):496-506. https:// doi.org/10.1097/01.prs.0000438056.67375.75

9. Manning AT, Sacchini VS. Conservative mastectomies for breast cancer and risk-reducing surgery: the Memorial Sloan Kettering Cancer Center experience. Gland Surg. 2016;5(1):5562. https://doi.org/10.3978/j.issn.2227-684X.2015.10.02

10. Orzalesi L, Casella D, Santi C, Cecconi L, Murgo R, et al. Nipple sparing mastectomy: surgical and oncological outcomes from a national multicentric registry with 913 patients (1006 cases) over a six year period. Breast. 2016;25:75-81. https://doi. org/10.1016/j.breast.2015.10.010

11. Dull B, Conant L, Myckatyn T, Tenenbaum M, Cyr A, Margenthaler JA. Nipple-sparing mastectomies: clinical outcomes from a single academic institution. Mol Clin Oncol. 2017;6(5):737-42. https://doi.org/10.3892/mco.2017.1208

12. Galimberti V, Vicini E, Corso G, Morigi C, Fontana S, et al. Nipple-sparing and skin-sparing mastectomy: review of aims, oncological safety and contraindications. Breast. 2017;34:S824. https://doi.org/10.1016/j.breast.2017.06.034

13. Wang M, Huang J, Chagpar AB. Is nipple sparing mastectomy associated with increased complications, readmission and length of stay compared to skin sparing mastectomy? Am J Surg. 2020;219(6):1030-5.https://doi.org/10.1016/j.amjsurg.2019.09.011

14. James PA, Mitchell G, Bogwitz M, Lindeman GJ. The Angelina Jolie effect. Med J Aust. 2013;199(10):646. https://doi. org/10.5694/mja13.11218

15. Tuttle TM, Abbott A, Arrington A, Rueth N. The increasing use of prophylactic mastectomy in the prevention of breast cancer. 
Curr Oncol Rep. 2010;12(1):16-21. https://doi.org/10.1007/ s11912-009-0070-y

16. Frasson AL, Lichtenfels M, Anton A, Souza AAB, Vollbrecht B. Risk-reducing mastectomy: a case series of 124 procedures in Brazilian patients. Breast Cancer Res Treat. 2020;181(1):69-75. https://doi.org/10.1007/s10549-020-05582-w

17. Valero MG, Muhsen S, Moo TA, Zabor EC, Stempel M, et al. Increase in utilization of nipple-sparing mastectomy for breast cancer: indications, complications, and oncologic outcomes. Ann Surg Oncol. 2020;27(2):344-51. https://doi.org/10.1245/ s10434-019-07948-x

18. Kopkash K, Pesce C, Sisco M, Poli E, Seth A. The modern approach to the nipple-sparing mastectomy. J Surg Oncol. 2020;122(1):29-35. https://doi.org/10.1002/jso.25909

19. FreyJD,SalibianAA,KarpNS,ChoiM. Theimpactofmastectomy weight on reconstructive trends and outcomes in nipplesparing mastectomy: progressively greater complications with larger breast size. Plast Reconstr Surg. 2018;141(6):795e-804e. https://doi.org/10.1097/PRS.0000000000004404

20. Tang R, Coopey SB, Colwell AS, Specht MC, Gadd MA, Kansal $\mathrm{K}$, et al. Nipple-sparing mastectomy in irradiated breasts: selecting patients to minimize complications. Ann Surg Oncol. 2015;22(10):3331-7. https://doi.org/10.1245/s10434-015-4669-y

21. Spear SL, Rottman SJ, Seiboth LA, Hannan CM. Breast reconstruction using a staged nipple-sparing mastectomy following mastopexy or reduction. Plast Reconstr Surg. 2012;129(3):572-81. https://doi.org/10.1097/ PRS.0b013e318241285c

22. Bartholomew AJ, Dervishaj OA, Sosin M, Kerivan LT, Tung SS, et al. Neoadjuvant chemotherapy and nipple-sparing mastectomy: timing and postoperative complications. Ann Surg Oncol. 2019;26(9):2768-72. https://doi.org/10.1245/ s10434-019-07418-4

23. DellaCroce FJ, Blum CA, Sullivan SK, Stolier A, Trahan C, et al. Nipple-sparing mastectomy and ptosis: perforator flap breast reconstruction allows full secondary mastopexy with complete nipple areolar repositioning. Plast Reconstr Surg. 2015;136(1):1e-9e. https://doi.org/10.1097/ PRS.0000000000001325

24. Galimberti V, Morigi C, Bagnardi V, Corso G, Vicini E, et al. Oncological outcomes of nipple-sparing mastectomy: a single-center experience of 1989 patients. Ann Surg Oncol. 2018;25(13):3849-57. https://doi.org/10.1245/s10434-018-6759-0

25. Garcia-Etienne CA, Cody Iii HS 3rd, Disa JJ, Cordeiro P, Sacchini V. Nipple-sparing mastectomy: initial experience at the Memorial Sloan-Kettering Cancer Center and a comprehensive review of literature. Breast J. 2009;15(4):440-9. https://doi.org/10.1111/j.1524-4741.2009.00758.x

26. Webb C, Gupta N, Kosiorek H, Cronin PA, Pockaj BA, et al. The effects of body mass index on operative time and outcomes in nipple-sparing mastectomy. Am J Surg. 2020;220(2):395-400. https://doi.org/10.1016/j.amjsurg.2019.12.011

27. Zheng Y, Zhong M, Ni C, Yuan H, Zhang J. Radiotherapy and nipple-areolar complex necrosis after nipple-sparing mastectomy: a systematic review and meta-analysis. Radiol Med. 2017;122(3):171-8. https://doi.org/10.1007/s11547-0160702-x

28. Gagliato DM, Gonzalez-Angulo AM, Lei X, Theriault RL, Giordano $\mathrm{SH}$, et al. Clinical impact of delaying initiation of adjuvant chemotherapy in patients with breast cancer. J Clin Oncol. 2014;32(8):735-44. https://doi.org/10.1200/ JCO.2013.49.7693

29. Lesage M, Pilloy J, Fleurier C, Cirier J, Jourdan ML, et al. Impact pronostique du délai d'induction de la radiothérapie adjuvante dans le cancer du sein. [Prognosis impact of breast cancer adjuvant radiotherapy delay]. Gynecol Obstet Fertil Senol. 2019;47(6):516-21. French. https://doi.org/10.1016/j. gofs.2019.03.001

30. Riba LA, Gruner RA, Fleishman A, James TA. Surgical risk factors for the delayed initiation of adjuvant chemotherapy in breast cancer. Ann Surg Oncol. 2018;25(7):1904-11. https://doi. org/10.1245/s10434-018-6351-7 